\title{
Preparation of Bakery Products Using Coconut Flour and Glycemic Response on Normal Healthy Adults
}

\author{
Lalitha Ramaswamy ${ }^{1}$ and Sinthuja. $\mathrm{R}^{2}$
}

\begin{abstract}
Bakery products are ideal foods through which nutrition can be delivered to the consumers in an acceptable form. The feasibility of incorporating coconut flour in bakery products has been studied. Four recipes namely; biscuit, wheat bread, pizza base and puff pastry were formulated using $10 \%, 20 \%$ and $30 \%$ levels of coconut flour by replacing the major flour of the recipe. Organoleptic evaluation of the products showed that the products were acceptable up to $30 \%$ level in biscuits, pizza base and puff pastry and up to $10 \%$ level in bread. ANOVA comparing the mean scores showed that there was significant difference in all the criteria. The digestible carbohydrate $(\mathrm{CHO})$ and energy content of the coconut flour incorporated products were less than the standard ones, while the fiber content was more. Glycemic response of $30 \%$ incorporated biscuits (which was selected to be the most acceptable from among the formulated products) in normal adults was found to be lower than the standard.
\end{abstract}

Keywords: coconut flour, bakery products, glycemic response

\footnotetext{
${ }^{1}$ Associate Professor, Department of Nutrition and Dietetics, PSG College of Arts and Science, Coimbatore, India. Email: lalitharam58@gmail.com

${ }^{2}$ Post Graduate Student, Department of Nutrition and Dietetics, PSG College of Arts and Science, Coimbatore, India.
} 


\section{Introduction}

Coconut flour (CF) is a byproduct of VCO process. It is a food grade product obtained after drying the residue in VCO or coconut milk processing. Coconut flour can be used in baked recipes. It is delicious, gluten free and health promoting food as it has high dietary fiber in making high nutritious breakfast bread (20 $25 \%$ blend with wheat flour), cookies, and pastries. The use of locally available coconut flour is indeed a great opportunity for import substitution and savings on foreign exchange ( $R$. Arancon, Jr., 2010).

Figure 1. Coconut Flour

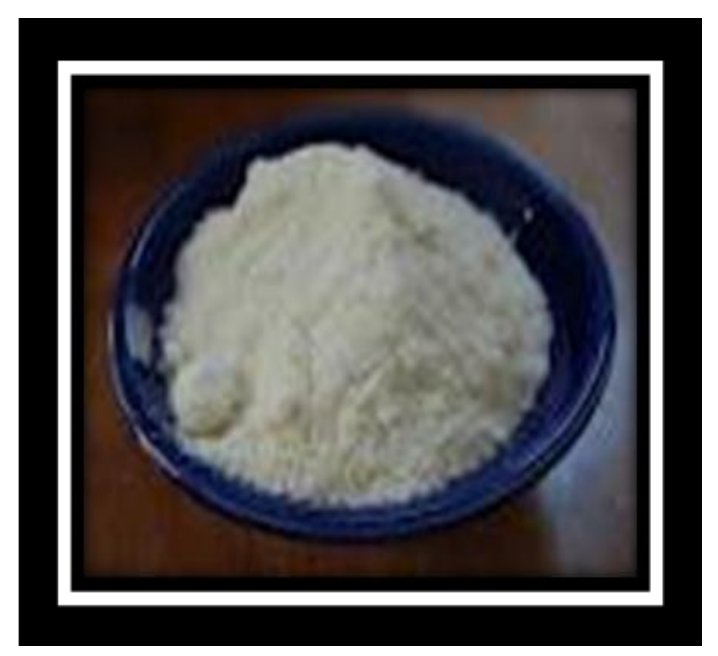

Coconut flour is made from one of the byproducts of coconut i.e., "sapal" the fluffy material left after the extraction of milk from grated coconuts by applying pressure. According to Ragavendra et al. (2004), sapal is then washed in hot water to decrease the oil content. This reduces the fat content considerably. This residue is sun dried for 48 hours and then ground. The flour obtained is stored at room temperature and used for various purposes (Ramaswamy, 2010).

Coconut flour can be added to bakery products such as cookies, bars, quick breads, desserts, muffins and for breading fish, chicken or vegetables (www.omeganutrition.com). It enhances the flavor of chocolate, vanilla while cooking or baking foods and improves the texture of baked foods. It can also be added to porridge, smoothies and desserts, casseroles and soups, as a thickener in sauces and gravies. It can be sprinkled on the morning cereal to add nutrients and fiber to the diet. It makes food naturally sweet and rich tasting (www.tianacoconut.com). Tropical organic coconut flour can be added to standard wheat- based recipes to add extra fiber, by substituting 10-30 percent of the grain based-flour with coconut flour. Tropical organic coconut flour is therefore 100 percent gluten free. Since organic coconut flour contains natural sugar from the coconut meat, baked goods need less sugar added. It has a mildly sweet coconut taste.

Low-carbohydrate bakery products have become very popular with the rise in the diabetic population. It has also gained importance because of its benefits in cardio vascular diseases, cancer of the GI tract and other conditions. Fibers act as bulking agents and serve to reduce the calorie content in food. The bulking nature and water retention properties of dietary fiber results in the formation of low calorie soft-type products that retains more moisture after baking and require lesser force to break than the control. Most commercially available "low-carb" or "reduced carb" bakery products are formulated with wheat protein isolate, soy protein isolate, or milk proteins as evidenced by the ingredient statements. To get more fiber and be healthier coconut flour can be used containing 60 percent total dietary, 56 percent of which is insoluble fiber, while the rest is soluble fiber. Like ordinary flour, it can be used as a main ingredient in making cookies, breads, muffins, pastries etc. Coconut flour is novel flour because it provides many health benefits beyond its nutritional content whose potential is yet to be tapped.

The study was conducted with the following objectives

- To formulate selected bakery products using coconut flour at different levels and evaluate their acceptability,

- To find out the glycemic response of the most acceptable product (prepared with $\mathrm{CF}$ ) in normal healthy adults. 


\section{Methodology}

Experimental design was the method used for carrying out the study and ethical clearance was got from Institutional Human Ethics Committee, PSG Institute of Medical Science and Research, Coimbatore.

Coconut Milk was extracted from grated coconuts by grinding them and the meal remaining called the "sapal" was washed in hot water to reduce the oil content. The residue was then sun dried for 48 hours and ground. The flour obtained was stored at room temperature and used for product formulation and further analysis.

Four bakery products namely biscuits (BC), wheat bread (WB), pizza base (PB) and puff pastry (PU) were prepared by incorporating coconut flour in varying proportions and compared with the standard. Maximum level of incorporation was up to 30 percent for the flours. In all the bakery products, the major flour was replaced with coconut flour. A standard product was also prepared for comparison. The blending ratio of baked foods is shown in Figure 2.

Figure 2. Blending Ratio of Baked Foods with $\mathrm{CF}$

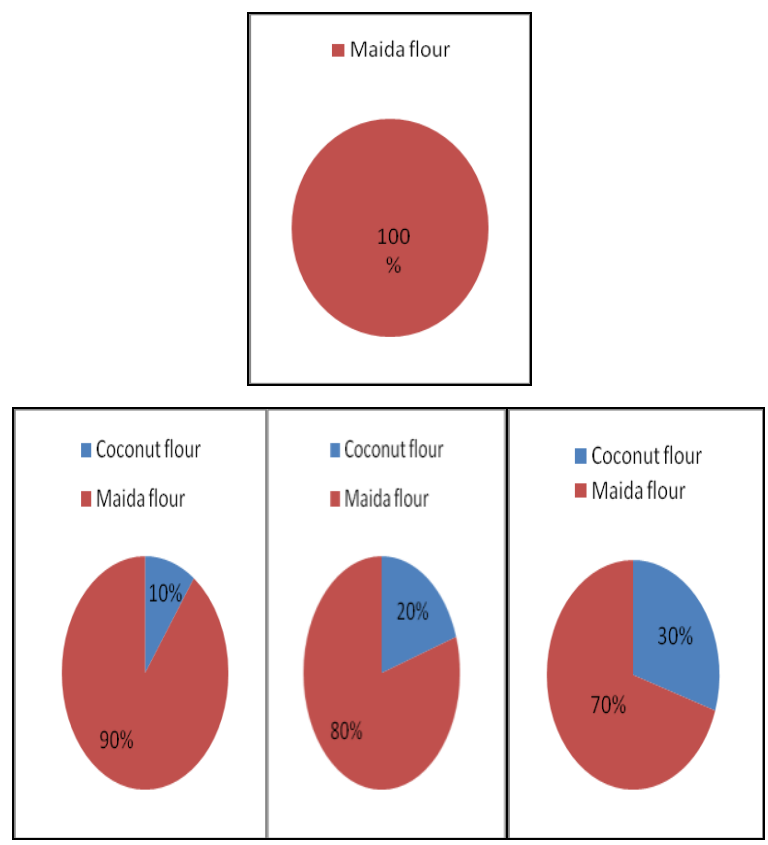

Plates 1, 2, 3, and 4 show bakery products prepared with coconut flour.
Plate 1- Biscuits
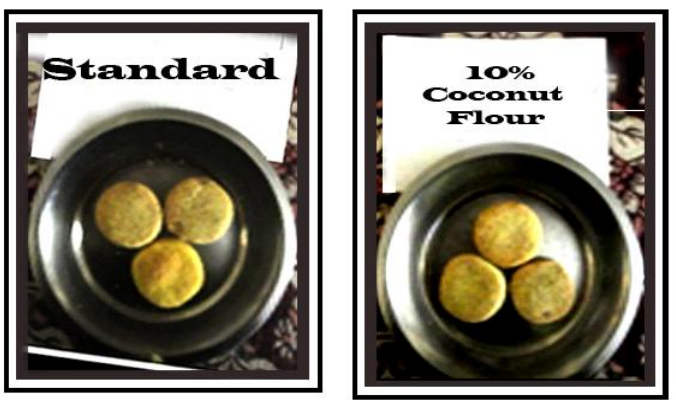

\section{Coconut Flourbiscuit}
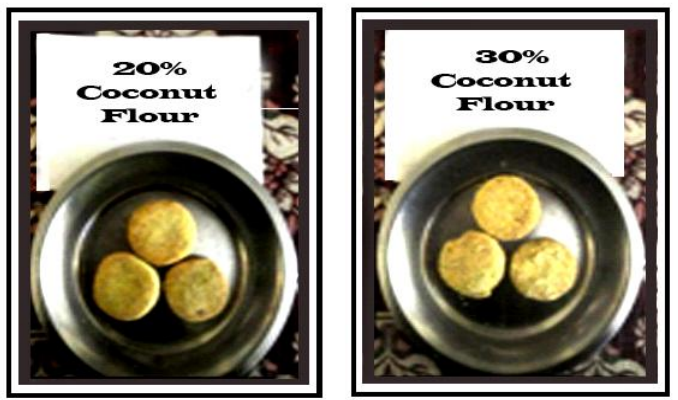

Plate 2 - Bread

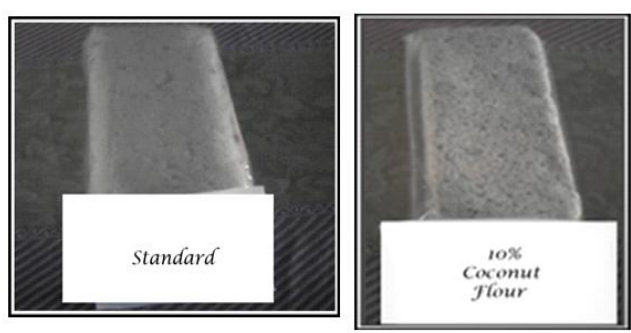

Coconut Flour Bread
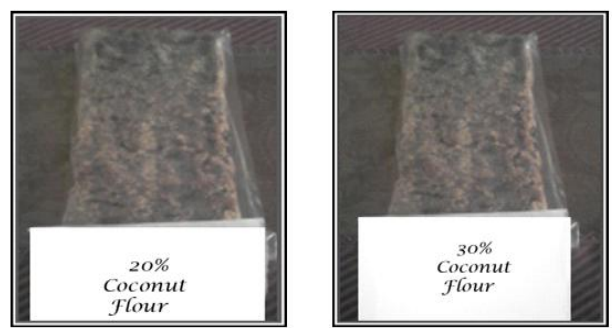
Plate 3 - Pizza Base
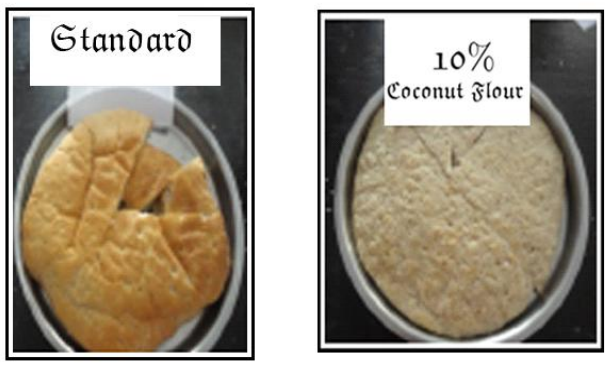

\section{$\mathfrak{P i z z} \mathfrak{a}$ With Coconut $\mathfrak{F l o u r}$}
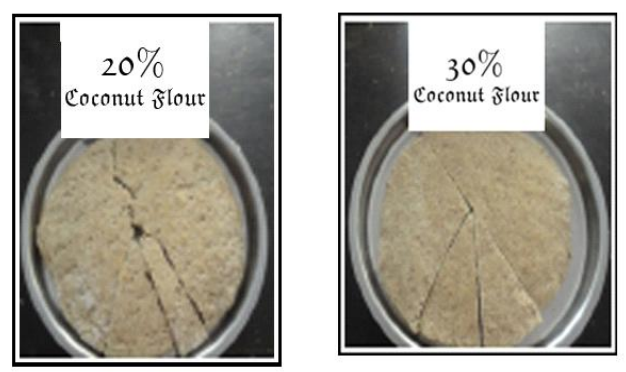

Plate 4 - Puff Pastry
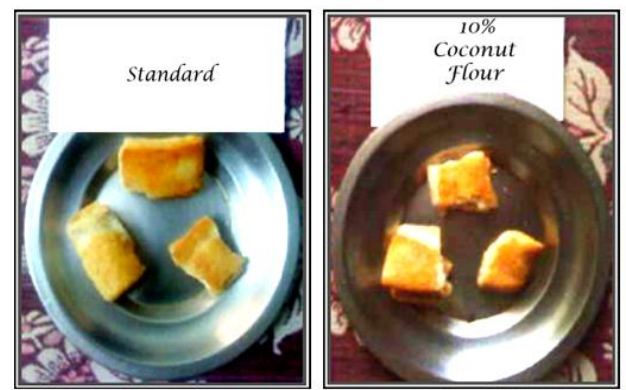

Coconut Flour Puff
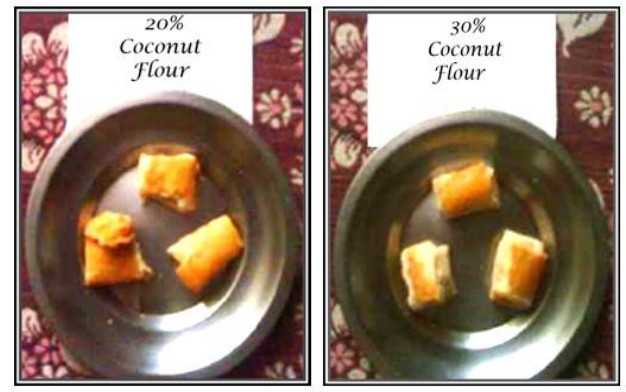

Organoleptic Evaluation of Prepared Bakery Products

The organoleptic evaluation of the four bakery products namely wheat bread, biscuit, pizza and puff pastries using coconut flour and the standard were evaluated by ten panel members using a five point hedonic scale score card. The samples were evaluated in the foods laboratory as per the standard techniques with each panel member evaluating the recipes in a confidential manner at $11.00 \mathrm{AM} / 3.00 \mathrm{PM}$ so that the member is neither too hungry nor too full at the time of evaluation.

\section{Selection of Recipes for Supplementation}

From among the evaluated recipes, only one from wheat bread (WB), biscuit (BC), pizza base (PB) and puff base (PU) made with coconut flour was selected as experimental food. From the recipes prepared, biscuits ie. BCCF3 (30\% $\mathrm{CF}$ incorporated) were selected for supplementation as they were found to be the most acceptable. Moreover, these biscuits being affordable happen to be the most widely consumed of all the biscuit varieties in the country.

\section{Quantification of Portion Size}

The amount of biscuits that was supplemented was based on the portion size. A pilot study was first conducted in order to quantify the portion size for an adult. Based on the pilot study it was derived that five biscuits $(62 \mathrm{~g})$ contributed to one portion (amount that could be consumed by an adult at a single time). The amount of digestible carbohydrates and fiber present in $62 \mathrm{~g}$ of biscuits are presented in Table 1.

Table 1. Nutrient Content of Biscuits (62gm)

\begin{tabular}{|l|c|c|}
\hline \multirow{2}{*}{ Biscuit } & \multicolumn{2}{|c|}{$\begin{array}{r}\text { Selected Nutrient Content } \\
\text { of Biscuit }\end{array}$} \\
\cline { 2 - 3 } & CHO (g) & Fiber (g) \\
\hline BC & 48.89 & 0.186 \\
BCCF3 & 40.86 & 8.27 \\
\hline
\end{tabular}




\section{Glycaemic Response of Standard and} Experimental Foods

Ten normal adult volunteers aged $20-35$ years were recruited for the study. All the subjects were in good health. Subjects on drugs that could affect carbohydrate metabolism and those with body mass index (BMI) $>30 \mathrm{~kg} / \mathrm{m}$ were excluded from the study. The age, height and weight were determined in all the subjects before the start of the study

After 10-12 hours over night fasting, the participants reported to the laboratory and randomly consumed within 15 minutes, the standard biscuits. The participants also received $200 \mathrm{ml}$. of water after consumption of biscuits. After ingestion, the participants remained in the laboratory for two hours for the assessment of glycemic response. Their blood was tested every half an hour for the glucose level using a glucometer. Following this, the participants were asked to pursue their normal activities.

After a wash out period of 48 hours, the participants reported to the laboratory and after testing their fasting blood glucose level they randomly consumed within 15 minutes, the quantified test biscuits (BCCF3) and their blood was tested for the glucose level every half an hour in the same way as for standard biscuits. Capillary finger-stick blood samples were taken in the fasting state $(0 \mathrm{~min}), 30,60,90$ and 120 minutes after the start of each meal. Blood glucose levels were measured using a Bayer' Breeze 2 glucometer (Plate 5) with the help of glucose strips (Reis et al., 2011). The positive areas under the curve (AUC) were computed by the trapezoidal method (FAO, 1998).

Plate 5

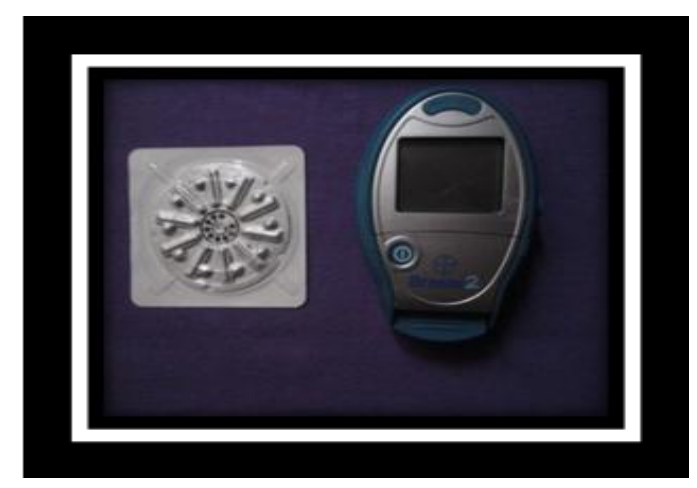

\section{Results and Discussion}

\section{Organoleptic Scores of BC}

BCF3 made with coconut flour had obtained highly acceptable scores compared to the other levels of incorporation. Thus it shows that no substantial change was observed by the addition of coconut flour in biscuits. Also the panel of judges observed that biscuits being a crisp product, addition of coconut flour up to 30 percent level were acceptable. Studies on development of high fibre soft biscuits indicated that flour could be substituted with raw wheat bran up to $30 \%$ level, as a source of dietary fiber, without affecting the overall quality (Leelavathi and Rao, 1993).

Okpala and Chinyelu (2011) opined that cookies from pigeon pea and cocoyam flour blends had improved protein content compared to cookies from wheat. Cookies with $20 \%$ pigeon pea had the highest in-vitro protein digestibility and the best sensory scores. It shows that cookies containing $20 \%$ pigeon pea flour and $80 \%$ cocoyam flour have great potentials and compare favorably with $100 \%$ wheat. Therefore biscuits prepared with coconut flour will contribute to the fiber content of the diet and be helpful to diabetics and aged population.

\section{Organoleptic Scores of Wheat Bread}

Wheat bread made with 10 percent $\mathrm{CF}$ (WBCF1) had got the maximum mean scores in all the criteria compared to WBCF2 and WBCF3 and was nearer to that of standard. The organoleptic scores obtained by the other two variations were less, thus showing that they were less acceptable. The addition of coconut flour in the preparation of wheat bread affected the film forming and stretching characteristics of gluten film thus lowering the loaf volume. The incorporation of coconut flour in wheat bread increased the hardness with increasing amount of coconut flour incorporation. The raw smell of coconut flour was observed in WBCF3 (30\% coconut flour incorporated bread). Ognean et al. (2006) have reported that at a level of 15 percent incorporation of bran, the sensorial acceptability of the outcome bread decreases very much and becomes almost unacceptable. Patek (1991) had 
Cord 2013, 29 (1)

Figure 3. Mean Scores of BC

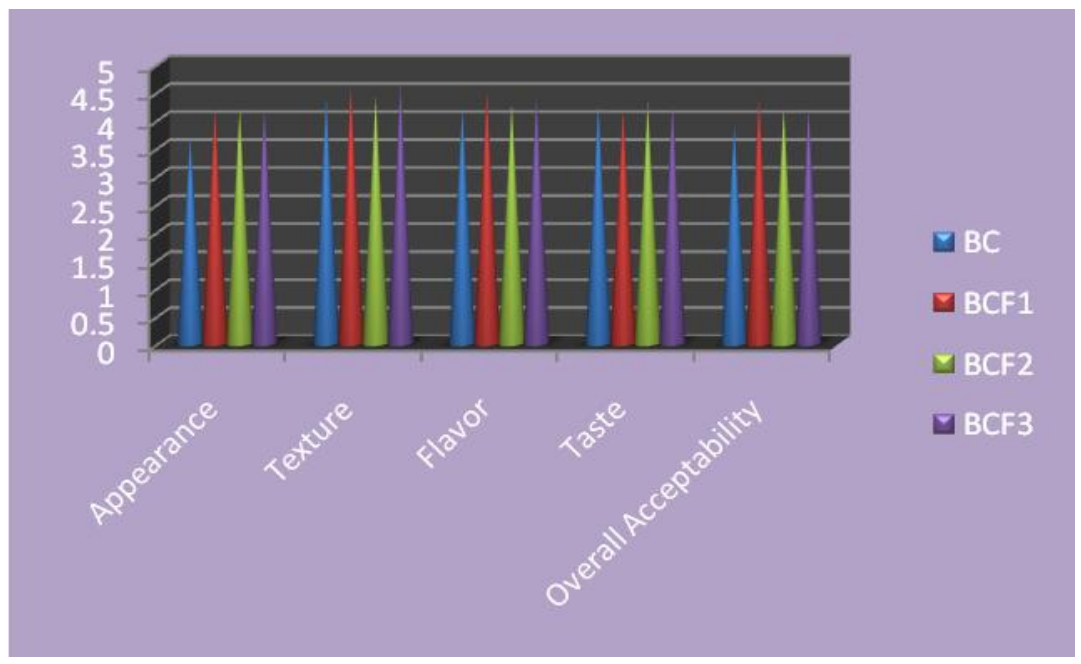

Figure 4. Mean Scores of WB

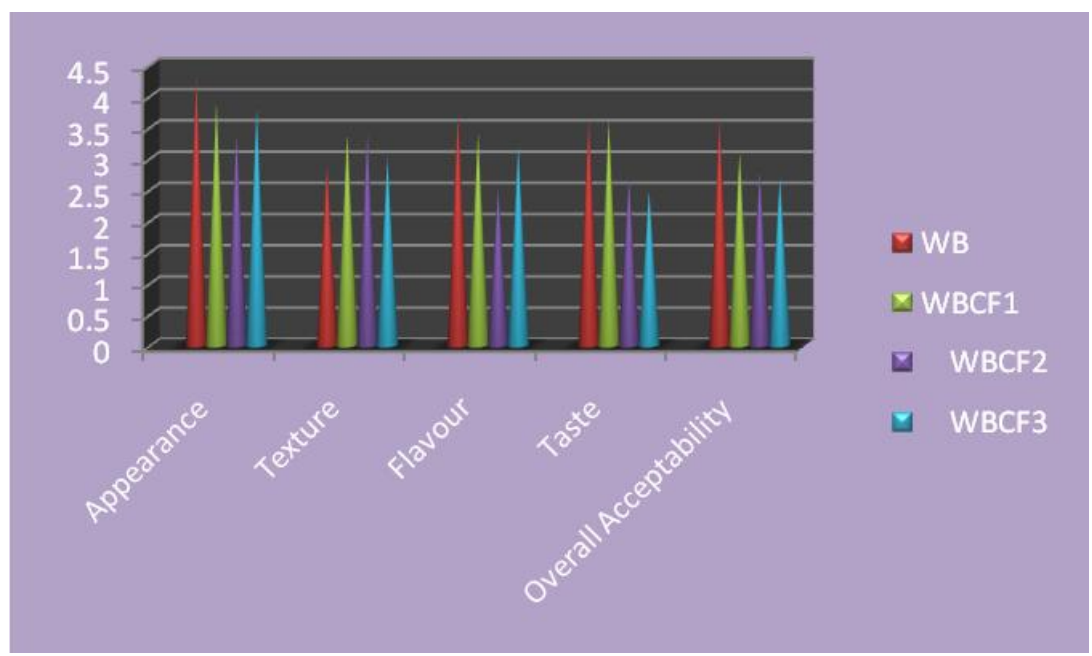

Figure 5. Mean scores of PB

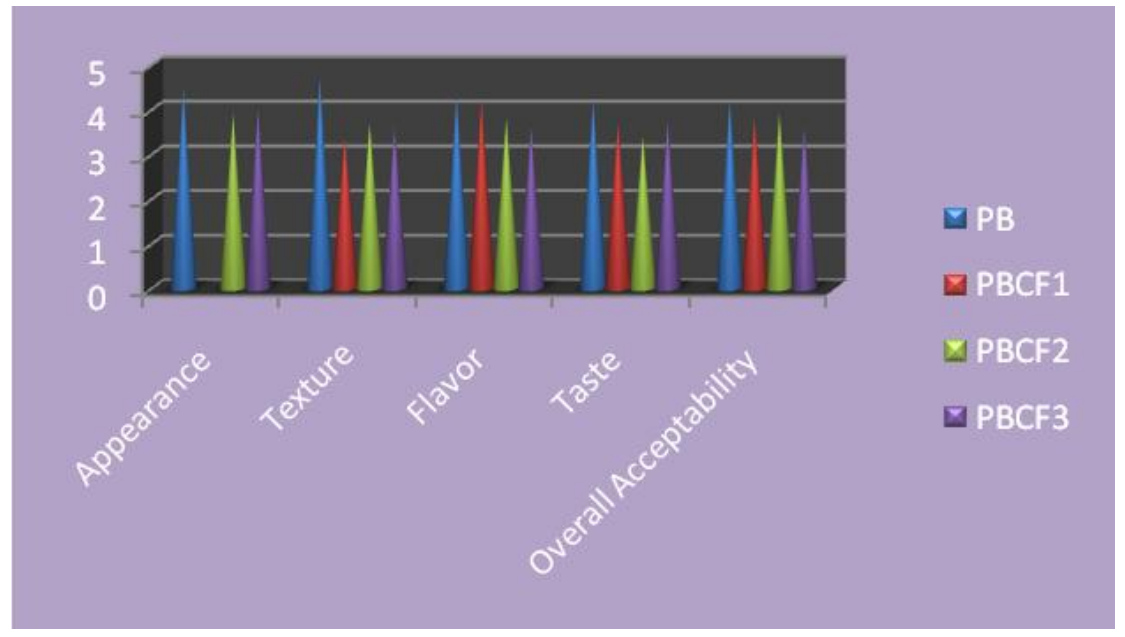


also observed that the addition of dietary fiber dilutes the gluten, while fiber particles affect the film forming and stretching characteristics of gluten film thus lowering loaf volumes.

However it may be inferred that preparation of coconut flour incorporated bread opens out another choice for the consumer to select from an array of high fiber bread available in the market as also echoed by Stewest (1990) who has said that the consumer has a choice of several bakery products which contribute some extra fiber than in standard white bread and that the typical levels are 1.4 per cent crude fiber and 5.2 percent dietary fiber in whole wheat bread. Wheat flour was gradually replaced with defatted rice bran (DRB) at different levels and the quality of bread can be improved by the addition of 5\% DRB having high fiber and mineral content for commercialization (Sharif et al., 2009).

Alldrick (2005) replaced 5 percent of the flour with one of these dietary fiber preparations (oat bran low dp-degree of polymerization, insulin and high dp insulin) plus a compensatory amount of gluten, and found an increase in dietary fiber content from 2.0 for the control bread to 2.3 percent for the oat bran supplemented bread and 4.25 percent for the insulin supplemented breads. In these cases, adding dietary fiber sometimes actually contributed to improve consumer acceptability.

\section{Organoleptic Scores of PB}

Pizza base made with PBCF2 (Figure 5) had obtained maximum meanscores compared to other levels of $\mathrm{CF}$ incorporation. The mean score for appearance of PBCF1 and PBCF3 was the same. The flavor of PBCF1 was much similar in comparison to the $\mathrm{PB}$. The mean scores for taste were equal in both PBCF1 and PBCF2. The products $\mathrm{PBCF} 1, \mathrm{PBCF} 2$ and $\mathrm{PBCF} 3$ were found to be harder, thus explaining the low scores obtained for texture. Rheological and functional properties of dough play an important role in governing the quality of baked products.

Randhwa and others (2002) studies 7 Pakistani wheat varieties namely Inqulab-91, Chenab-2000, Iqbal-2000, Auqab-2000 and T95713 which were collected from Punjab and V-
7002 and V-7003 were collected from Sind. These varieties were evaluated for rheological, functional and baking properties. Sensory parameters of pizza before and after baking revealed that Auqab-2000, Iqbal-2000 and Chenab-2000 exhibited longer shelf life for pizza dough-base as well as overall acceptability of pizza.

The quality of pizzas is influenced by the flour used for the base. The addition of CF in the pizza base has affected the acceptability to a certain extent. However, this is another way by which the fiber content can be increased, thus improving the health promoting factors of pizza. The investigator observed that the baking time increased parallelly along with coconut flour.

\section{Organoleptic Scores of PU}

Puff base (Figure 6) made with various levels of $\mathrm{CF}$ was almost like that of the standard. The mean scores of texture and flavor of PUCF3 were the highest while the mean scores for appearance of PBCF3 was the same as that of the standard. The panel of judges opined that PUCF3 was crisper and found it to be more acceptable.

Figure 6. Mean Scores of PU

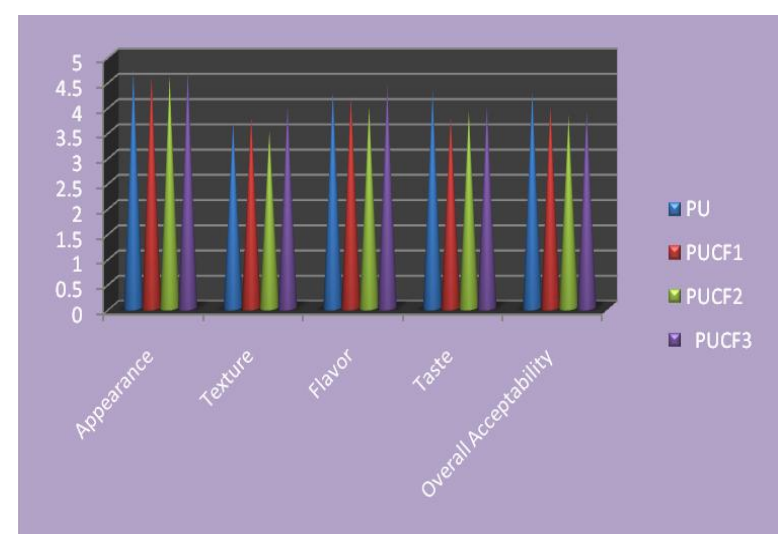

ANOVA comparing organoleptic scores of the products shows that there is a significant difference between the standard and variations.

\section{Nutrient content of Most Acceptable Bakery Products (per 100g)}

The nutrient content of most acceptable bakery products in comparison with the standard is presented in Table 2 . 
Table 2. Comparison of Selected Nutrients of Standard and Most Acceptable Recipe Prepared with CF

\begin{tabular}{|l|l|r|r|r|r|c|}
\hline \multirow{3}{*}{ S. No } & \multirow{2}{*}{ Recipe } & \multicolumn{5}{|c|}{ Nutrients } \\
\cline { 3 - 7 } & & $\begin{array}{c}\text { CHO } \\
(\mathrm{g})\end{array}$ & $\begin{array}{c}\text { Protein } \\
(\mathrm{g})\end{array}$ & $\begin{array}{c}\text { Fibre } \\
(\mathrm{g})\end{array}$ & $\begin{array}{c}\text { Fat } \\
(\mathrm{g})\end{array}$ & $\begin{array}{c}\text { Energy } \\
(\mathrm{g})\end{array}$ \\
\hline \multirow{2}{*}{1.} & BC & 78.87 & 11.0 & 0.30 & 50.90 & 997.0 \\
\cline { 2 - 7 } & $\begin{array}{l}\text { BC-CF3 } \\
(30 \%)\end{array}$ & 74.53 & 12.1 & 4.66 & 50.81 & 783.1 \\
\hline \multirow{2}{*}{2.} & WB & 302.54 & 42.4 & 6.65 & 35.95 & $17,19.8$ \\
\cline { 2 - 7 } & $\begin{array}{l}\text { WB-CF1 } \\
(10 \%)\end{array}$ & 287.60 & 39.5 & 21.35 & 32.84 & $1,605.0$ \\
\hline \multirow{2}{*}{3.} & PB & 78.87 & 11.0 & 0.6 & 10.90 & 457.9 \\
\cline { 2 - 7 } & $\begin{array}{l}\text { PB-CF2 } \\
(20 \%)\end{array}$ & 69.66 & 12.0 & 9.02 & 10.72 & 388.3 \\
\hline \multirow{2}{*}{4.} & PU & 73.90 & 11.0 & 0.3 & 70.90 & 978.0 \\
\cline { 2 - 7 } & $\begin{array}{l}\text { PU-CF3 } \\
(30 \%)\end{array}$ & 69.65 & 12.0 & 4.66 & 70.81 & 943.2 \\
\hline
\end{tabular}

The digestible $\mathrm{CHO}$ and energy content of all coconut flour (CF) incorporated products were less than the standard ones, while the fiber content of the $\mathrm{CF}$ incorporated products was more. The fiber content of CF incorporated WB was three times more than the standard while that of the other three products had increased more than ten times. This increased fiber content is highly beneficial to those suffering from obesity, CV diseases and diabetes mellitus. The protein content of CF incorporated products was slightly greater than the standard (except wheat bread). The fat content did not show much change except in the case of wheat bread where there was a reduction of 3 percent.

Fiber adds no calories to the diet and has been proven valuable in the management of weight loss, coronary heart diseases, diabetes, hypertension and stroke. Adding fiber to the diet decreased food intake and subjects on a reduced caloric diet reported diminished hunger after supplementing with fibers. Thus, fiber may assist in weight management programs by promoting a feeling of fullness, decreasing hunger, and promoting adherence to a reduced caloric diet (Laifer, 2005). Joseph (2007) has shown that an additional 14 grams of fiber daily is associated with a 10 percent decrease in caloric intake and a resulting loss in body weight.
The adlibitum low fat, high fiber diet promoted weight loss patients with type 2 diabetics without causing unfavorable alterations in plasma lipids or glycemic control (Grehard et. al., 2004). A growing number of metabolic research studies have reported total cholesterol reductions of 10 to 15 percent with diets, enriched with fiber from oats, beans, or psyllium, but these diets were also reduced in fat. Other studies have investigated adding supplements of protein and guar gum with subsequent cholesterol reductions of 10 percent or more, but gastro intestinal side effects were more common (Horn, 2000).

Bakery products made with coconut flour blends have additional advantages, suggesting their use in medical nutrition therapy for treating diabetes, cardio vascular diseases and for conditions like constipation and obesity.

\section{Results of Glycemic Response}

Table 3. Results of Glycemic Response of BC and $\mathrm{BCCF} 3$

\begin{tabular}{|l|c|c|c|c|}
\hline \multirow{2}{*}{} & \multicolumn{4}{|c|}{ Paired T-tes } \\
\cline { 2 - 5 } & $\begin{array}{c}\text { No. of } \\
\text { sample }\end{array}$ & Mean & SD & SEM \\
\hline $\begin{array}{l}\text { Glycemic } \\
\text { Response } \\
\text { of BC }\end{array}$ & 10 & 24.3380 & 1.9383 & 0.6129 \\
\hline $\begin{array}{l}\text { Glycemic } \\
\text { Response } \\
\text { of BCCF3 }\end{array}$ & 10 & 24.0460 & 1.3147 & 0.4158 \\
\hline
\end{tabular}

Figure 7. Mean Glycemic Response of $\mathrm{BC} \&$ $\mathrm{BCCF} 3$

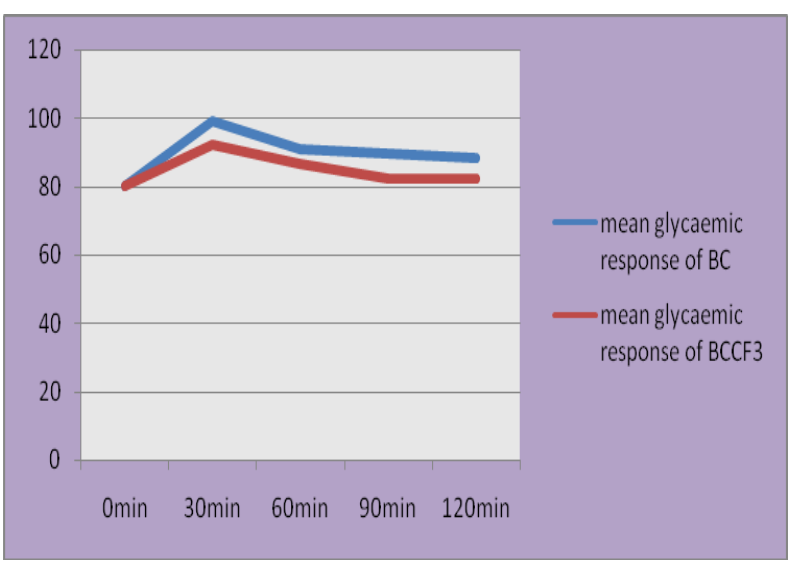


The mean glycemic response of coconut flour incorporated biscuits (Table 3 and Figure 7) was less than that of the standard (BC), thus showing that the fiber in coconut flour has helped in reducing the glucose level. When the levels of coconut flour in these products are increased to a greater level, further decrease in glycemic response can be noticed. Trinidad (2003 and 2001) has reported that increasing the levels of coconut flour has great significance in the proper control and management of diabetes mellitus and maintenance of weight. The glycemic index of coconut flour products in normal and diabetic subjects with increasing levels of dietary fiber determined in ten normal and ten diabetic subjects showed that the glycemic index of coconut flour supplemented foods decreased with increasing levels of dietary fiber from coconut flour. Dietary fiber controls the release of glucose with time, thus helping in the proper control and management of diabetes mellitus. Chandalia et. el. (2000) have ascertained that increases in fiber from a variety of dietary sources improves glycemic control in type 2 diabetes.

\section{Conclusion}

Coconut Flour (CF) is suitable for incorporation up to 30 percent in biscuits, pizza base and puff pastry and 10 percent level in bread. The proportion of $\mathrm{CF}$ can be increased beyond 30 percent in biscuits, pizza base and puff pastry. The fiber and protein content of $\mathrm{CF}$ incorporated products were higher, while energy, fat and digestible $\mathrm{CHO}$ lower. Glycemic response of $\mathrm{CF}$ incorporated product is lower than the standard. The results of the study on the use of coconut flour to get high-fiber baked products of satisfactory quality would benefit the bakery industry and the high dietary fiber content of the products indicates their use for cardiovascular patients, diabetics and also for conditions such as constipation and obesity.

\section{References}

Alldrick, A.J. 2005. The Bakery: a Potential Leader in Functional Food Application. (www.functionalfoodnet.eu accessed on 03.02.12).
Chandalia M, A. Garg, D. Lutjohann, K. von Bergmann, S.M. Grundy and L.J. Brinkley. 2000. Beneficial Effects of High Dietary Fiber Intake in Patients with Type 2 Diabetes Mellitus. N Engl J. Med., 342: pp1392-1398.

FAO. 1998, Carbohydrates in Human Nutrition. Food and Nutrition Paper No 66. Report of a Joint FAO/WHO Expert Consultation. Rome.

Grehard G.T., Ahmann and others. 2004. Low Fat Compared with High Mono-Diets in Diabetes. American Journal of Clinical Nutrition., 80: Pp668-673.

Horn L.V. 2000. A Statement for Health Care Professionals from the Nutrition Committee. American Heart Association (circ.ahajournals.org), accessed on 25.02.12

Joseph. 2007. Nutrition and Dieetics $\left(2^{\text {nd }}\right.$ ed). Tata MC Graw Hill Publishing Company Limited., Pp526, 86, 87.

Laifer, S. 2005. New Findings on Fiber. Le Magazine (www.lef.org), accessed on 26.02.12

Leelavathi S. and K. Rao. 1993. Development of High-Fiber Biscuits Using Wheat Bran. Journal of Food Science and Technology, 30 (3): Pp187-190.

Ognean, M., N. Darie and C.F. Ognean. 2006. Studies about Obtaining Low Calorie and High Fiber Content Bakery Product Using Wheat Bran. Acta Universitatis Cibiniensis., Seria F Chemia 9: Pp55-66.

Okpala, L.C. and V.A. Chinyelu. 2011. Physicochemical, Nutritional and Organoleptic Evaluation of Cookies from Pigeon Pea (Cajanuscajan) and Cocoyam (Xanthosomasp) Flour Blends. African Journal of Food, Agriculture, Nutrition and Development., 11 (6): Pp1684-1686 .

Patek J. 1991. Preparation of Low Caloric Fiber Rich Bread. Nutrition \& Food Science., 35 (7): Pp432-438. 
Randhawa, M.A., F.M. Anjum and M.S. Butt. 2002. Physico-chemical and Milling Properties of New Spring Wheats Grown in Punjaband Sind for the Production of Pizza. Int. J. Agric. Biol., 4: Pp482-484.

Ragavendra, S.N., N.K. Rastogi, K.S.M. Ramarav and others. 2004. Dietary Fiber from Coconut Residue, Effects of Different Treatments and Particle Size of the Hydration Properties. European Food Research and Technology, 218(6): Pp563567.

Ramaswamy. 2010. Coconut Flour-Its Nutritive Value, Health Benefits and Culinary Applications. In a Nutshell, Pp126-128.

Romulo Jr., N.A. 2010. Global Coconut Scenario Trends and Opportunities. In a Nutshell, Pp 11-27.

Reis and others. 2011. Ground Roasted Peanuts Leads to a Lower Post-prandial Glycemic Response than Raw Peanuts. Nutr Hosp., 26(4): P 318.

Shariff, M.K., S. Masood, Butt, F.M. Anjum Haq Nawz. 2009. Preparation of Mineral and Fiber Enriched Defatted Rice Bran Supplemented Cookies. Pakistan Journal of Nutrition, 8(5): Pp571-577.

Small Industries Service Institute, 2000. (www.sisi.com) accessed on 10.12.11

Stewest, G.A. and R. Phersonskey. 1990, Medical Aspects Dietary Fiber. Plenum Medical Book Company., New York, Pp214-215.

Trinidad, T.P., D.H. Valdey, A.S. Loyallo, and Mallillin. 2003. Glycaemic Index of Coconut Flour Products in Normal and Diabetic Subjects. British Journal of Nutrition, Pp551-556

Trinidad, T.P., D.H. Valdez and A.C. Mallin. 2001. Coconut Flour from Residue: A Good Source of Dietary Fibre. Indian Coconut Journal, 35 (5): Pp9-13.

\author{
WwW.omeganutriton.com \\ accessed \\ on \\ 11.08.2011 \\ www.tiana-coconut.com \\ accessed on
}

